\title{
The Joint Influence of Online Rating and Product Price on Purchase Decision: An EEG Study
}

This article was published in the following Dove Press journal:

Psychology Research and Behavior Management

Lijun Sun'

Yin Zhao ${ }^{2}$

Bin Ling ${ }^{3}$

'CAS Key Laboratory of Behavioral Science, Institute of Psychology/Department of Psychology, University of Chinese Academy of Sciences, Beijing, People's Republic of China; ${ }^{2}$ Furnishing and Industrial Design School, Nanjing Forestry University, Nanjing, People's Republic of China; ${ }^{3}$ School of Business, Hohai University, Nanjing, People's Republic of China
Correspondence: Bin Ling

Room I 103, Boxue Building, Focheng

West Road, Nanjing City, People's

Republic of China

Tel +86-025-685I 4352

Email ling.bin@hotmail.com
Background: Consumers had to encounter and consider product-oriented and revieworiented cues before making an online purchasing decision. It was important to resolve how these cues influenced consumers' online purchasing decision. We also knew little about how the human brain processed these cues simultaneously, and which cue would occupy a dominant position in neural activity. The purpose of the present study was to investigate the neural correlates of online shopping decisions and how online rating and product price jointly influenced such purchase decisions.

Research Method: Eighteen undergraduates were recruited to participate in this research. Each participant was exposed to all four experimental conditions combining 2 (product price: high vs. low) $\times 2$ (online rating: positive vs. negative) with a total of 192 trials. They were required to rate the degree of willingness-to-pay. EEG data were obtained with 64 electrodes placed on the Easy Cap according to the International 10-20 system. We conducted both the event-related potentials analysis and the time-frequency analysis for the EEG data.

Results: The behavioral findings indicated that products with positive rating and low price increased the willingness-to-pay. The EEG results showed that larger late positive potentials were elicited by products with low price compared with high price under positive rating condition, but not under negative rating condition, reflecting the modulated effect of online rating on the emotional arousal elicited by product price. Furthermore, we found larger alpha event related desynchronization elicited by products with positive rating compared with negative rating, indicating that more cognitive resources were allocated for products with a positive rating.

Conclusion: Combined with behavioral and EEG analysis, our results emphasized the more important position of product rating compared with price. The findings deepened the understanding of the neural mechanisms underlying the online shopping decision process. More attention should be paid to online ratings on the webpage of the electronic store, because negative ratings made a product less appealing for prospective consumers regardless of price. Thus, the owners should build good reputations for their online products, which were fundamental to the consumers' online purchasing decisions.

Keywords: online rating, product price, neural mechanism, LPP, alpha-ERD

\section{Introduction}

With rapid development of e-commerce platforms like Amazon and Alibaba, online shopping services have become extremely convenient and efficient in modern life. There was a massive amount of cues (i.e., advertising, price, sales, reviews) used on the shopping websites explicitly or implicitly influencing buyers' purchase behavior regarding a product. These cues were found to stimulate or dampen people's desire for dazzling merchandise and influence their subsequent shopping behavior. ${ }^{1,2}$ 
Online cues were classified into product-oriented cues (i.e., product price, production area) and review-oriented cues (i.e., customer rating, message) in previous research. ${ }^{3}$ Some studies mainly focused on only one type of cues (product-oriented or review-oriented) while others emphasized coordination of both types of cues. These two streams of research have generally been beneficial for a better understanding of how online cues influenced online shopping decision making. The first stream investigated separately the effect of product-oriented cues or review-oriented cues on purchasing decision. Prior research has also provided lots of empirical evidence for this proposition and has recognized the important positions of product price, ${ }^{4,5}$ product quality, ${ }^{6}$ sales volume, ${ }^{7}$ and customer ratings ${ }^{8}$ in the process of online buying. Therefore, the authors posited that the product information was especially effective during online shopping. These cues can independently predict subsequent purchasing behavior even at the neural level. For example, Knutson et $\mathrm{al}^{4}$ found that product preference and price could activated the nucleus accumbens and the insula region respectively, the activation of which could independently predict consumers' purchasing decision.

Another stream examined the synergistical effects of product-oriented cues and review-oriented cues on purchasing decision. This approach posited that these different oriented cues could not stand alone when consumers encountered a purchasing situation, whereas multiple cues could compose various profiles where cues interacted closely with each other in the process of product evaluation and decision making. In fact, online purchase decision was a rather complicated process. Most buyers had to repeatedly weigh consumer reviews (e.g., online rating) against the value of the product (e.g., product price). Because product price and online rating reflected consumers' perceived quality and perceived value of products, these cues could determine the process of how to select and purchase merchandise from e-commerce stores. ${ }^{1,9}$ Research from Kostyra et $\mathrm{al}^{1}$ indicateed that the positive effect of price on customer purchasing probability could decrease as online consumer rating was available. Neural studies also provided neuroscientific evidence that the activities in distinct neural circuits correlated with specific product cues and review cues when choosing online products. ${ }^{10-12}$ These studies indicated a trade-off process between product price and online rating in an online shopping context, which required consumers to think carefully before making decisions.
Although the interlinked nature of product price and online rating has been significantly recognized in prior studies, we were still far from understanding the neural mechanism of how price cue and online rating jointly influenced people's purchasing decision. We also knew little about how the human brain processes these cues simultaneously, and which cue would occupy a dominant position in neural activity. The purpose of this study was to clarify how the brain responded to these two kinds of cues simultaneously by exploring the neural correlates of online shopping decision jointly influenced by product price and online rating.

This study contributed to the literature on product cues and purchase decision in the following points. On the one hand, our study focused on product rating and price cues to investigate the simultaneous influence on the tendency of willingness-to-pay for the products. The interactive effect between online rating and product price was beneficial to understand which cues could invoke more dominant neural activity underlying purchase decision. Based on the behavioral and neural findings we could also figure out the optimal combination of different cues, which would have important implications for online websites and sellers. On the other hand, this study contributed to the effects of online cues on purchase decision by clarifying the time courses of the cognitive and emotional responses of neural activities, because decision was a complex process involving both of them. ${ }^{13}$ In terms of shopping decision, exposure to product cues before purchasing was usually accompanied with activities, such as emotional arousal, short-term memory, review valence categorization (RVC) process, and attitude experience. Our brain will calculate and process different combinations of online cues before making a purchase decision, eliciting different neural components. Therefore, we believed that the neural analysis of cognitive and emotional processing were important for understanding the influence of online cues on purchase decision.

In our study, we used the EEG (Electroencephalograph) technique to explore the neural mechanism underlying the online shopping decision process. EEG had high temporal resolutions, which helped us accurately track the dynamic time course of brain processes. ${ }^{14,15}$ We believed that the neural evidence could provide a channel for better understanding the joint effects of multiple online cues on purchase decision. Considering the important role of product price and online rating in shopping decision, ${ }^{1,16,17}$ we manipulated product price and online rating with a $2-$ by- 2 
experimental design where participants had to encounter four different cue profiles. Positive/negative price generally represented high/low product quality, while high/low price represented large/small cost for consumers. The purchase decision was made by rating the willingness-to-pay for the products based on those different profiles of cues. The task could elicit both emotional and cognitive activity toward product items, which could also be revealed by the neural responses. Based on the analyses of the main effects of review and price, the influences of the two kinds of cues on purchase decision were determined. Furthermore, we would also figure out which cue had a dominant role by interactive effect and comparing the responses to a product with negative review but low price, or with positive review but high price. The implication of this research would benefit online buyers when searching and selecting product items from online stores.

We believed that different profiles of rating and price were likely to elicit various emotional and cognitive responses toward product items. It was not hard to infer that people would be willing to purchase a product with low price and positive rating and reluctant to buy a product with high price and negative rating. Meanwhile, we hypothesized that product price would have an interactive effect with online rating on consumers' online purchasing decision. The profiles of this interactive effect may be reflected in the late postive potential (LPP) component and alpha band, which corresponded to emotional and cognitive processing in the brain, respectively. ${ }^{18-23} \mathrm{We}$ hypothesized that the products with low price would elicit larger LPP than high price under positive rating conditions, reflecting the difference of emotional arousal. Furthermore, given the cognitive implication of alpha band power, ${ }^{21,22,24}$ we hypothesized that the products with positive ratings would elicit larger alpha-event related desynchronization (ERD) than negative ratings in order to allocate more cognitive resources.

\section{Method}

\section{Participants}

This study recruited eighteen undergraduates (11 females) who participated in return for $50 \mathrm{RMB}$ from Hohai University. Their ages were distributed from 20 to 26 years old $\left(M_{\text {age }}=23.21\right.$ years, $\left.S D=2.49\right)$. All participants were right-handed and had normal or corrected-to-normal vision, and they also reported no history of neurological, major medical or psychiatric disorders or hearing impairments in their past. All of them reported online shopping experience and almost spent an average of 10 hours shopping online each week in the last half year. All participants signed a written informed consent before joining the experiment. The Ethical Research Committee of Hohai University approved this study in accordance with the Helsinki Declaration for the protection of human subjects in research.

\section{Stimulus}

Given the generalization of experimental stimulus, we selected six types of online products including notebooks, vacuum cup, pens, headsets, mouse and flash disk, which fell within the scope of undergraduates' daily commodities. We firstly selected 300 product pictures as our targeted stimuli and each type included 50 pictures. All these materials came from well-known online shopping platforms such as Amazon, E-bay, and Taobao. We adopted a standardized procedure to edit these pictures so that they could have similar physical features (e.g., shape, size) and the same image resolution ( 800 pixels by 800 pixels). We also controlled the range of product price which could fall within 250 RMB. Thus, 48 products ( 8 products each type) were picked up with an average price of $76 \mathrm{RMB}$ (from 7 RMB to $228 \mathrm{RMB}$ ).

We built the graph of star rating following the rating system of the Amazon website. The rating was classified as four levels of rating, including one-star, two-star, four-star and five-star. The one- and two-star ratings were manipulated as the negative-rating condition, whereas four- and five-stars were defined as the positive-rating condition. As for the manipulation of product price, we used a floating strategy to define the product price. For both the high and low price, 15 percent of fluctuation was varied around the reference price, which was the actual price presented on the websites. Half of the items (96 trials) had price over the original price with a 15 percent increase, and the other half of the items (the other 96 trials) had price under the original price with a 15 percent decrease. Therefore, the price was parametrically varied. In our study, product price and online rating were orthogonally combined into four experimental conditions, as follows: a) high-price and positive-rating condition, b) highprice and negative-rating condition, c) low-price and positiverating condition, and d) low-price and negative-rating condition. Finally, 192 trials (48 products $* 4$ conditions) were included in the experiment, with each product corresponding to four conditions. 


\section{Procedure}

First, participants were required to complete a questionnaire about their demographics and online shopping habits. The items included the time/money they spent in online shopping, their concerns about product price and review, and the possibility of online shopping. The data indicated that the amount of time participants spent on online shopping per day was more than half an hour on average, and the consumption per month was more than 500 RMB. They reported a possibility of online shopping of over 80 percent in daily life. Meanwhile, all their concerns about product price and review were rated as more than seven points on 10-point Likert scales during online shopping process. The results of the questionnaire indicated that our participants had high engagement in online shopping behavior and paid close attention to the product price and review.

The trial structure was depicted in Figure 1. First, a red fixation cross was presented in the center of a grey screen for 1000 milliseconds (ms), which was followed by a product image lasting $1000 \mathrm{~ms}$. And then a reference price was presented in the center of the screen for $1500 \mathrm{~ms}$, indicating an average product price. After the reference price, an image of rating star was presented for $1500 \mathrm{~ms}$, and the actual selling price followed lasting for $1500 \mathrm{~ms}$. Finally, participants were required to assess the degree to which they wanted to buy on a 5-point Likert scale by pressing one of the keys on the keyboard with unlimited duration $(0=$ strongly unwilling, $5=$ strongly willing). The whole experiment was separated into four blocks by rests. Forty-eight trials in each block were arranged in a pseudo-random order with constraints so that the same product could not appear in neighboring trials, and each condition could not appear in more than three consecutive trials. Before the formal experiment, participants were guided through eight practice trials in order to familiarize them with the experimental task and procedure.

\section{ERP Recording and Analysis}

EEG data were obtained with 64 electrodes placed on the Easy Cap according to the International 10-20 system (Brain Vision, Morrisville, NC). Horizontal eye movements were monitored with an electrode on the outer canthi of the right eye. Blinks and vertical eye movements were recorded with an electrode below the left eye. The EEG signal was digitized at a rate of $500 \mathrm{~Hz}$ and with an amplifier band-pass of $0.01-100 \mathrm{~Hz}$ together with a $50 \mathrm{~Hz}$ notch filter. Impedance levels were kept below $10 \mathrm{k} \Omega$.

For the ERPs analysis, the data were referenced offline to the algebraical mean of left and right mastoid electrodes, filtered offline with a band-pass filter of 0.1 to $30 \mathrm{~Hz}$ (24-dB/oct slope) using Brain Vision Analyzer 1.05. ERPs time-locked to the onset of the actual price were averaged for each participant under each condition. Epochs of 1700 msec (including a $200 \mathrm{msec}$ pre-stimulus period) were averaged and epochs were baseline-corrected using the $200 \mathrm{~ms}$ prior to the onset of the final price. We used independent component analysis (ICA) algorithm to correct the eye-blink and horizontal eye movements. Trials were discarded due to excessive physiological noise if they

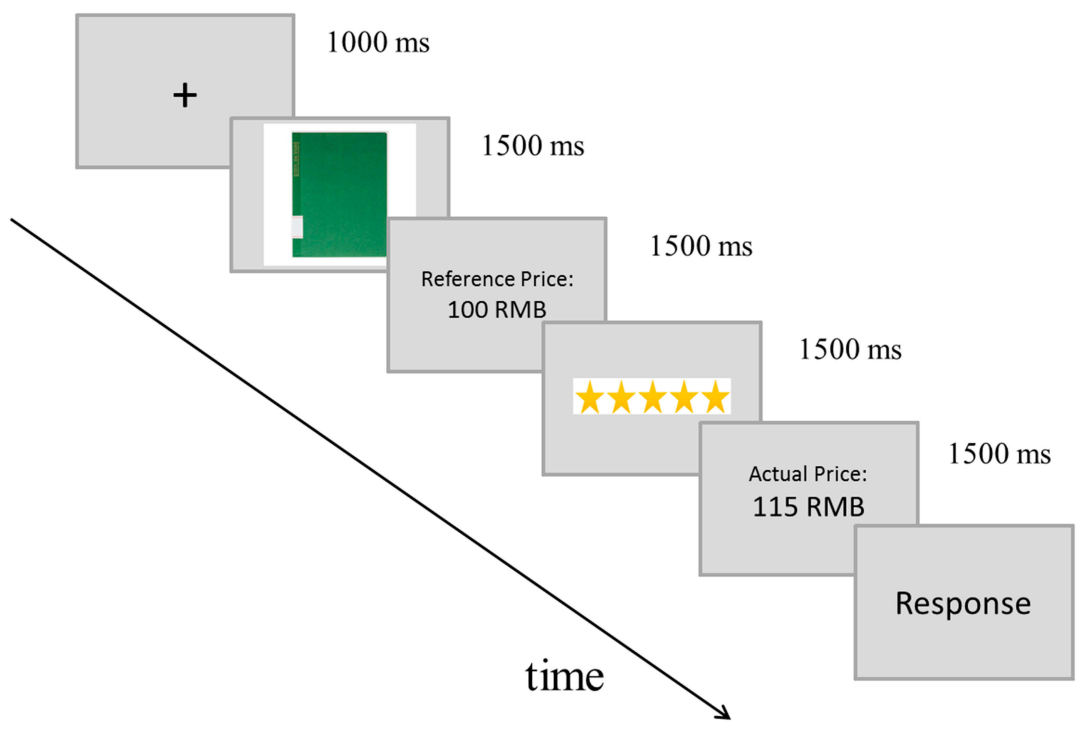

Figure I Illustration of the experimental trial structure. 
contained: i) a voltage step $>50 \mathrm{mV} / \mathrm{ms}$ between sample points, ii) a $\max -\min$ difference $>100 \mathrm{mV} / \mathrm{ms}$ within a 200 window, and iii) low activity $(<0.5 \mathrm{mV} / \mathrm{ms})$ within a $100 \mathrm{~ms}$ window. Based on the typical scalp distribution and latency of the LPP component in previous research, ${ }^{25}$ CPZ, CP1, CP2, PZ, P1, P2 electrodes and 500-1000 ms were chosen as regions of interests (ROIs).

For the time-frequency analysis, the continuous data were first filtered with a band-pass between 1 and $100 \mathrm{~Hz}$ and segmented into epochs of $3000 \mathrm{~ms}$ ranging from $1000 \mathrm{~ms}$ before the onset of final price to $2000 \mathrm{~ms}$ after the onset of actual price. All EEG trials were baseline corrected using the $1000 \mathrm{~ms}$ pre-stimulus interval. Then, trials were corrected using ICA algorithm implemented in EEGLAB (EEGLAB 10.2.5.5b, http://www.sccn.ucsd.edu/eeglab) to delete ocular and muscle artifacts. Subsequently, any trials with amplitudes exceeding $100 \mathrm{mV}$ were excluded. Finally, to obtain timefrequency distributions, fast Fourier transforms (FFTs) with a fixed 400 ms Hanning window were applied to all the timefrequency points in the average epochs across trials for each subject (in steps of $2 \mathrm{~ms}$ in the time domain, and $1 \mathrm{~Hz}$ in the frequency domain). In order to exclude the influence of the variability of pre-stimulus and post-stimulus EEG activities, we used 800 to $200 \mathrm{~ms}$ interval for the baseline correction. Based on the visual inspection of the resulting spectrogram, we chose the alpha band $(8-13 \mathrm{~Hz})$ and central-parietal electrodes including CPZ, CP1, CP2, PZ, P1, P2 as ROIs, which were analyzed in the two time windows of 500-1000 $\mathrm{ms}$ and 1000-1500 ms separately.

For both ERPs and time-frequency analysis, repeated measures ANOVAs considering rating (positive, negative) and price (high, low) as within-subject factors were conducted, which were followed by simple effects tests if twoway interactions were significant.

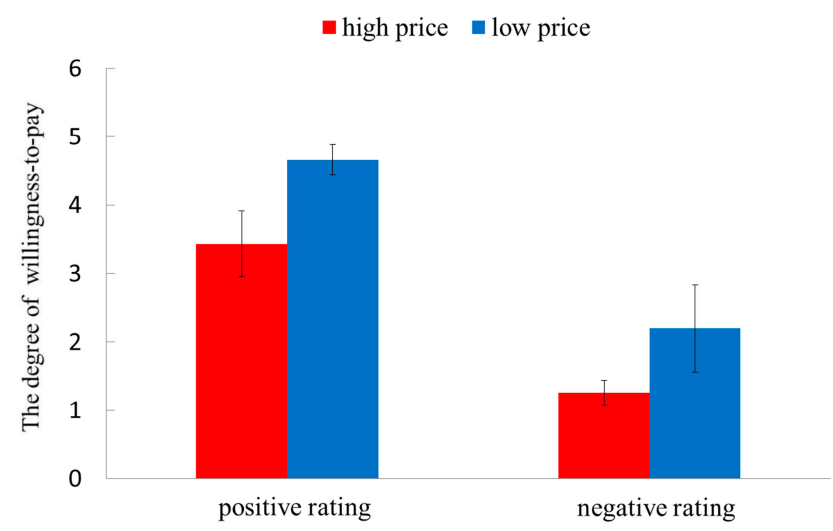

Figure 2 Mean ratings of the degree of willingness-to-pay across four conditions.

\section{Results}

\section{Behavioral results}

The willingness-to-pay across each condition was shown in Figure 2. There were significant main effects of rating $\left(F_{(1,17)}=312.72, p<0.001\right.$, partial $\left.\eta^{2}=0.95\right)$ and price $\left(F_{(1,17)}=76.20, p<0.001\right.$, partial $\left.\eta^{2}=0.82\right)$, reflecting that positive rating (positive: $M=4.05, S D=0.72$; negative: $M=1.73, S D=0.66$ ) and low price (high: $M=2.35$, $S D=1.15$; low: $M=3.43, S D=1.32$ ) improve participants' likelihood of buying. Moreover, there was an interaction effect between rating and price $\left(F_{(1,17)}=10.32, p=0.005\right.$, partial $\eta^{2}=$ $0.38)$. The following simple effect analysis found that the effects of price were significant under both positive rating $\left(F_{(1,17)}=\right.$ 107.76, $p<0.001$, partial $\left.\eta^{2}=0.86\right)$ and negative rating $\left(F_{(1,17)}=\right.$ 42.72, $p<0.001$, partial $\eta^{2}=0.72$ ) conditions. Meanwhile, the effects of rating were also significant under both high price $\left(F_{(1,17)}=298.72, p<0.001\right.$, partial $\left.\eta^{2}=0.95\right)$ and low price $\left(F_{(1,17)}=270.08, p<0.001\right.$, partial $\left.\eta^{2}=0.94\right)$ conditions. The mean value and standard deviation for the four conditions were as follows: high price and positive rating: $M=3.43, S D=0.12$; high price and negative rating: $M=1.26, S D=0.05$; low price and positive rating: $M=4.66, S D=0.05$; low price and negative rating: $M=2.20, S D=0.15$.

\section{EEG Results ERP Results}

Figure 3 showed the ERP waveforms at posterior midline electrode site $(\mathrm{Pz})$ under four conditions. The amplitude of the late positive potentials elicited by the products with positive review and high price was the smallest compared with other three conditions. Figure 4 showed the scalp distributions of the low minus high price difference waves under the positive and negative review conditions, respectively. In the time window of 500-1000 ms, the late positive component elicited by price was distributed in the occipital-parietal electrodes under positive rating condition, but not under negative rating condition.

For the time window of 500-1000 ms, a two-way ANOVA revealed an interaction effect between rating and price $\left(F_{(1,17)}=6.27, p=0.023\right.$, partial $\left.\eta^{2}=0.27\right)$. Simple effect test suggested that under positive rating conditions, the late positive potentials elicited by products with low price were more positive compared to high price $\left(F_{(1,17)}=7.46, p=0.014\right.$, partial $\eta^{2}=$ $0.31)$. However, under negative rating conditions, there were no significant difference between high and low price $\left(F_{(1,17)}=0.64\right.$, $p=0.435$, partial $\left.\eta^{2}=0.04\right)$. Neither the main effects of the rating nor the price were significant (rating: $p=0.18$; price: $p=0.97$ ). 


\section{positive rating}

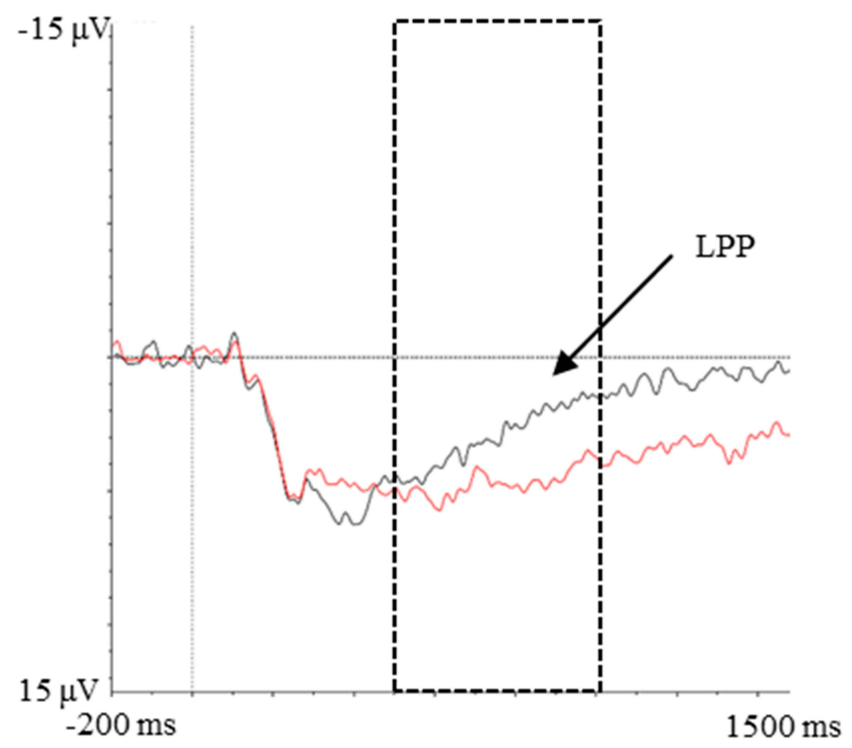

negative rating

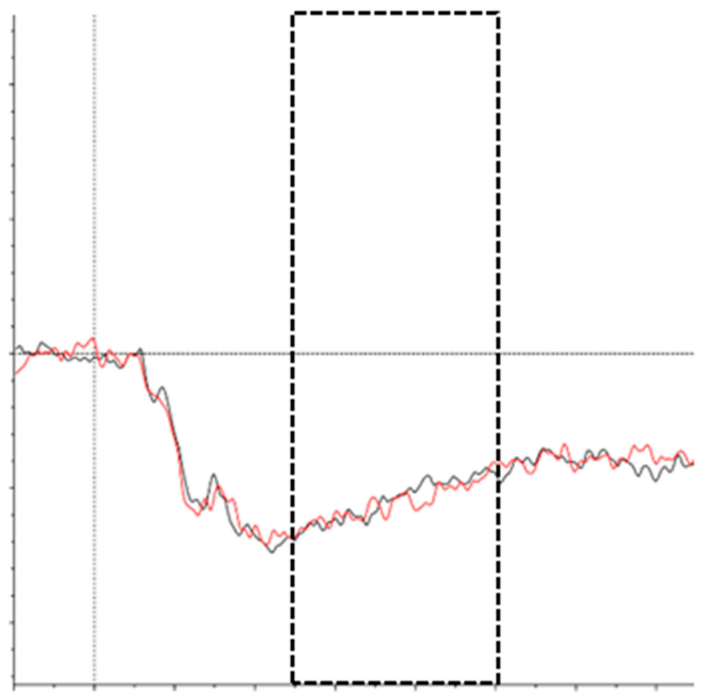

low price

high price

negative rating

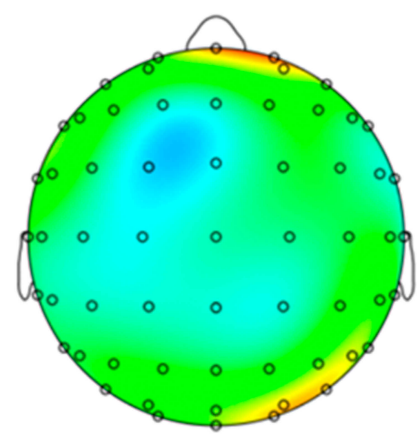

$\begin{array}{ccc}-2 \mu \mathrm{V} & 0 \mu \mathrm{V} & 2 \mu \mathrm{V} \\ & 500-1000 \mathrm{~ms} & \end{array}$

Figure 4 Scalp distributions of the low price minus high price difference waves under the positive and negative rating conditions in the $500-1000$ ms.

\section{Time-Frequency Results}

The spectrogram representing signal power at each timefrequency point from 1 to $100 \mathrm{~Hz}$ and from -1000 to $2000 \mathrm{~ms}$ sampled at the posterior midline electrode site
(Pz) in four conditions was shown in Figure 5, from which we could see the different alpha-ERDamong four conditions. Figure 6 shows the topography of alpha-ERD from 8 to $13 \mathrm{~Hz}$ under positive and negative rating 
positive rating, high price
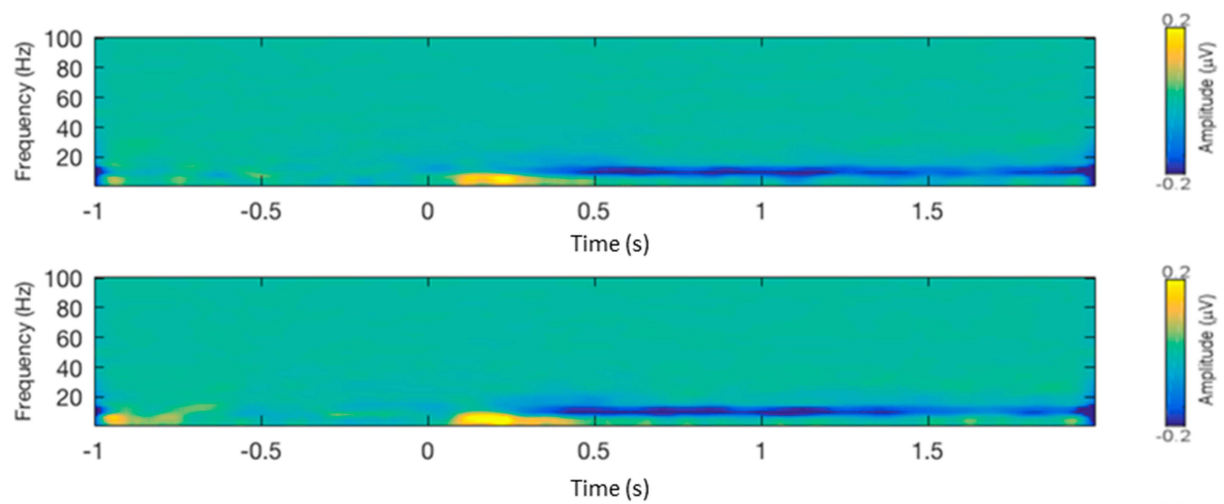

positive rating, low price
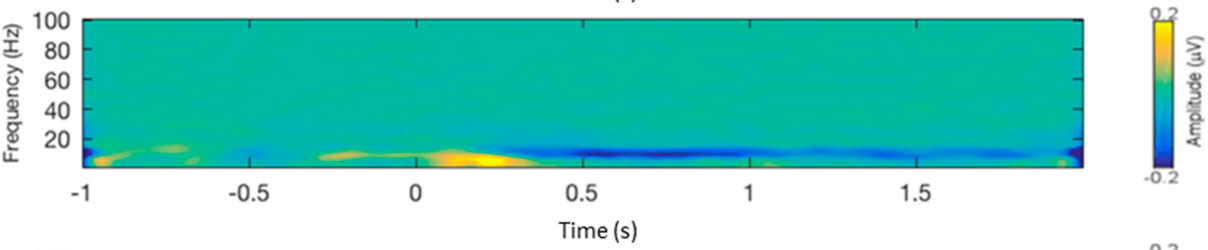

negative rating, high price
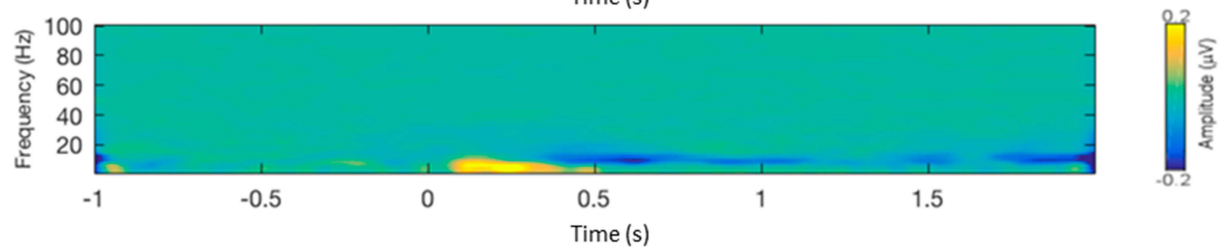

Figure 5 The spectrogram at each time-frequency point at $\mathrm{Pz}$ electrode site in four conditions.
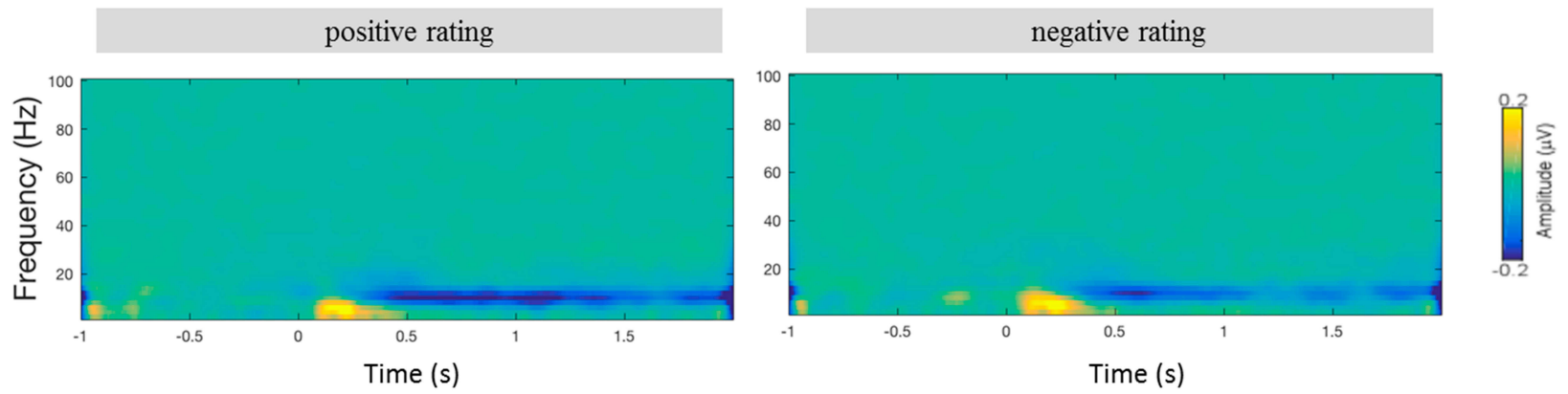

8-13 Hz:

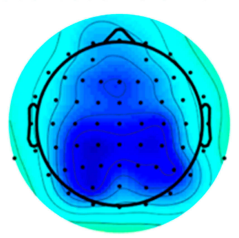

$500-1000 \mathrm{~ms}$

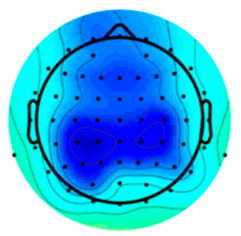

$1000-1500 \mathrm{~ms}$

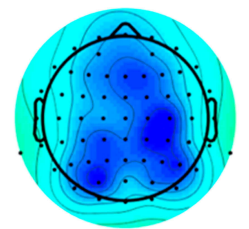

$500-1000 \mathrm{~ms}$
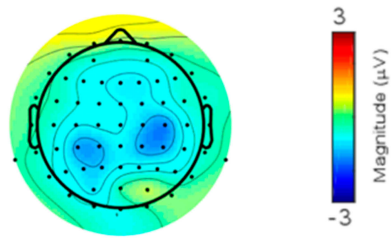

1000-1500 ms

Figure 6 The spectrogram of the positive and negative rating conditions (average across different price) at Pz electrode site, and the topography of the alpha-ERD from 8 to $13 \mathrm{~Hz}$ in the time windows of $500-1000 \mathrm{~ms}$ and $1000-1500 \mathrm{~ms}$.

condition (averaged across high and low price). The alpha-ERD under positive rating condition was larger than that under negative rating condition, which was mainly distributed in the central-parietal electrodes in both the time windows of $500-1000 \mathrm{~ms}$ and 1000-1500 ms.

Two-way ANOVAs revealed a main effect of rating for both the time window of $500-1000 \mathrm{~ms}\left(F_{(1,17)}=5.31\right.$, 
$p=0.034$, partial $\left.\eta^{2}=.24\right)$, and the time window of $1000-1500 \mathrm{~ms}\left(F_{(1,17)}=4.73, p=0.044\right.$, partial $\left.\eta^{2}=.22\right)$, suggesting that the alpha-ERD elicited by positive rating condition was larger than that elicited by negative rating condition. However, the main effects of price and the interaction effect between the price and rating were not significant in the time window of 500-1000 ms (main effect of price: $p=0.98$; interaction effect: $p=0.30$ ) and $1000-1500 \mathrm{~ms}$ (main effect of price: $p=0.59$; interaction effect: $p=0.19$ ).

\section{Discussion}

The present study adopted EEG technique to investigate the neural correlates of the joint effects of product price and rating during online shopping decision. Behaviorally, we found that the product price and rating had significant main effects on purchase decision. This finding indicated that products with positive rating and low price could increase participants' likelihood of buying. Importantly, the EEG results showed an interaction effect between online rating and product price. The late positive potentials elicited by the low price were larger than the high price under positive rather than negative rating conditions, suggesting the modulated effect of online rating on emotional arousal elicited by price. In the time-frequency domain, we found larger alpha-ERD elicited by prodcuts with positive rating compared with negative rating, indicating that more cognitive resources were allocated for products with positive rating. However, there were no differences in the alpha-ERD under high price and low price conditions. The results indicated the dominant position of online rating over product price. The main results were discussed as follows.

\section{Implication for Research}

Behavioral results indicated that low product price and positive online rating had promoting influences on participants' purchase decision. The results were consistent with previous studies, supporting the important role of product price, ${ }^{4,5}$ and customer ratings ${ }^{8}$ in the process of online buying. The tendency toward low price was related to cost avoidance and the tendency toward positive rating might be associated with quality seeking. Interestingly, the results suggested that products with high price and positive rating were more likely to be bought compared with low price and negative rating (the willingness-to-buy: 3.43 vs. 2.20 ). Our results demonstrated that consumers might attach great importance to product quality, and thus the products with positive product rating had more attraction compared with low price. Therefore, we provided empirical evidence about how participants decided when there were some conflicts between product price and review.

Based on the morphology and latency, the late positive potential was supposed to be the LPP component. In terms of topography, the LPP had a maximum effect in the central parietal electrodes in our study, which were also accorded with the typical scalp distribution of the LPP component. ${ }^{17,25,26}$ In terms of latency, the LPP component always developed approximately $300 \mathrm{~ms}$ after stimulus onset and lasted for hundreds of milliseconds to seconds. ${ }^{18,19}$ Similarly, the LPP occurred around $300 \mathrm{~ms}$ after the actual price onset and was sustained to $1500 \mathrm{~ms}$ in our study. In order to be consistent with previous studies, ${ }^{18,19}$ we selected the typical LPP time window of 500-1000 ms.

In our study, the influences of the product rating and price had an interactive effect on the LPP amplitude. The influence of the online rating on the effect of price was also found by a previous study. ${ }^{1}$ It has been demonstrated that larger LPP response had a close association with emotionally intense stimulus, reflecting higher emotional arousal. ${ }^{23,27}$ For example, the LPP amplitude can be enhanced when participants were exposed to affective scenes rather than neutral ones. ${ }^{28}$ In our experiment, product price and rating cues acted as emotional stimulus and elicited different emotional arousals. The emotional responses during the purchase decision were supported by a previous study, which found that the product price activated brain regions responsible for emotional processing. ${ }^{4}$ Thus, given the neural significance of the LPP, ${ }^{23,29}$ the differences of the LPP amplitude across the four conditions revealed the different affective responses of consumers.

The interaction results suggested that on the one hand, the participants experienced high emotional arousal when they faced products with negative rating regardless of price; on the other hand, under positive rating conditions products with low price but not high price could elicit high emotional arousal levels. Based on the behavioral ratings of $f$ the willingness-to-buy (high price and positive rating: 3.43 ; low price and negative rating: 2.20 ), we ascribed the former as positive valence, and the latter as negative valence. Indeed, positive emotional responses were associated with products that were preferred ${ }^{30}$ and with good review cues. ${ }^{31}$ Our results further indicated that lowering price could hardly compensate for the disadvantage of negative rating, however, positive rating made participants feel less satisfied when appended to high price. In general, the modulated 
effect of online rating on emotional arousal elicited by price implied the prominent role of product rating.

Importantly, our findings provided an additional theoretical explanation for price effect in prior research. According to prior research, price was a key determinant of consumer decision, but it worked in different presentations which were framed as discount or occurred at different stages of decision making., ${ }^{5,26}$ The emotional implication of the LPP component indicated that although low price was effective, it did not always work and was influenced by product ratings. In particular, participants expressed the preference for products with low price and positive rating but not for products with low price and negative rating. However, it was worth noting that the research of price-quality heuristic has received some attention in the consumer field, ${ }^{32-34}$ and there were disagreements about the proxy of high price for product quality. Therefore, it was necessary for future studies to consider the asymmetric effects of quality and price.

In addition to LPP components, EEG power was also an important measure to reflect the performance of cortical information processing. ${ }^{35}$ In our study, the alpha-ERD was larger under the positive rating condition than the negative rating condition, reflecting that positive rating evoked more alpha suppression and larger brain activity. Previous studies have found that the alpha rhythms were broadly associated with attention and memory processing, and the magnitude of alpha-ERD was positively correlated with cognitive processing. ${ }^{21,22,24,36-38}$ Online purchase decision involved a complex cognitive process where working memory system and long-term memory system jointly interacted with each other. Our findings suggested that positive rating would trigger more mental activity during the process of online shopping decision, based on the cognitive implication of alpha-ERD. In other words, more attentional resources were allocated for products with positive ratings, whereas less cognitive resources were required for products with negative ratings.

To take a further step, the final purchasing decision involved many processes including review valence categorization (RVC), short memory maintaining of the product rating, comparison between the reference price and actual price, and the decision making. The modulation of product rating on the alpha-ERD revealed the importance of the RVC process, which derived from classifying online cues and deliberative cognitive responses of evaluative categorization. The retrieving of the RVC in working memory required more cognitive effort for products with positive ratings than negative ratings. In contrast, the influence of the price on the alpha-ERD was absent. It might be due to the fact that regardless of products with high or low actual price, the process of comparison between the reference price and the actual price always existed.

Different from the LPP component, the lack of interaction effect on the alpha-ERD was mainly due to the different psychological processing. The LPP effect reflected the product preference and emotion arousal. However, the alpha-ERD reflected cognitive operations including the comparison of prices and the RVC. Participants had to conduct the mental calculation under both high and low price conditions, therefore, there was no interactive effect for the alpha-ERD. Indeed, previous studies also demonstrated that time-domain analyses and time-frequency analyses might reflect different aspects of brain processing. ${ }^{39,40}$

In general, among the combinations of the product rating and price, the profile of low price and positive rating was an optimal shopping situation for consumers. Our findings demonstrated that the combination of rating and price cues could simultaneously activate both cognitive and emotional responses. The predominance of the product rating was supported by both the modulated role of product rating in the emotional arousal elicited by product price and the influence of product rating on the cognitive processing.

\section{Implication for Practice}

Through uncovering the underlying neural mechanism, the results helped us have a deeper understanding of shopping decision process, and meanwhile had some important practical implications for online sellers. Given the fact that both online rating and product price had large effects on online shopping decision, the sellers should try their best to improve the online rating and relatively lower the product price. However, when there was a trade-off between the two factors, the appropriate choice for the online sellers was to improve the online rating, building a buyer's trust in the seller's credibility, rather than lowering the price to attract consumers. This was due to the fact that regardless of whether the price was high or low, a product with negative rating had no opportunity to be considered by prospective consumers, while a product with positive rating can differentiate among competitive sellers and create price premiums as returns for their reputation. Thus, our results showed sellers that improving product rating was a prerequisite to succeed and essential to be competitive in the Internet era. 


\section{Limitation and Future Research}

Future studies can further explore the role of the text comments, the consumers' individual difference and the long-range ERP components. First, this study only focused on online rating and product price. Future studies should broaden the scope of consumer reviews and product information. Beyond numerical ratings, text comments are more useful in offering fine-grained information about a seller's prior transactions that cannot be fully captured with crude numerical ratings. Second, all the participants were university students, who had limited purchasing power. Considering the individual differences in the price-comparison preference in various sub-populations (i.e., male and female, young and old people), future research should pay attention to the neural mechanism underlying the decision process involved in different groups of people. Finally, there is also a late LPP that extends to about $2000 \mathrm{~ms}$ after the stimulus onset and reflects different mental processes. However, in our study the experimental design did not allow us to analyze the time window after $1500 \mathrm{~ms}$, because the response interface appeared $1500 \mathrm{~ms}$ after the onset of the actual price. Future studies could adopt appropriate experimental design to examine both the early and late responses.

\section{Funding}

We received financial supports for this research from the National Natural Science Foundation of China (grant number: 71502048) and the Fundamental Research Funds for the Central Universities (grant number: 2018B20714).

\section{Disclosure}

The authors report no conflicts of interest in this work.

\section{References}

1. Kostyra DS, Reiner J, Natter M, Klapper D. Decomposing the effects of online customer reviews on brand, price, and product attributes. Int J Res Mark. 2016;33(1):11-26. doi:10.1016/j.ijresmar.2014.12.004

2. Wang QZ, Meng L, Liu ML, Wang Q, Ma QG. How do social-based cues influence consumers' online purchase decisions? An event-related potential study. Electron Commer Res. 2016;16(1):1-26. doi:10.1007/ s10660-015-9209-0

3. Hernández-Ortega B. Don’t believe strangers: online consumer reviews and the role of social psychological distance. Inf Manag. 2017.

4. Knutson B, Rick S, Wimmer GE, Prelec D, Loewenstein G. Neural predictors of purchases. Neuron. 2007;53(1):147-156. doi:10.1016/j. neuron.2006.11.010

5. Karmarkar UR, Shiv B, Knutson B. Cost conscious? The neural and behavioral impact of price primacy on decision making. J Soc Mark Res. 2015;52(4):467-481. doi:10.1509/jmr.13.0488

6 . Tsiotsou R. The role of perceived product quality and overall satisfaction on purchase intentions. Int J Consum Stud. 2006;30(2):207-217. doi:10.1111/ijc.2006.30.issue-2
7. Huang J-H, Chen Y-F. Herding in online product choice. Psychol Mark. 2006;23(5):413-428. doi:10.1002/(ISSN)1520-6793

8. Sun M. How does the variance of product ratings matter? Manage Sci. 2011;58(4):696-707. doi:10.1287/mnsc.1110.1458

9. Li X, Hitt LM. Price effects in online product reviews: an analytical model and empirical analysis. MIS Q. 2010;34(4):809-831. doi:10.2307/25750706

10. Bai Y, Yao Z, Cong F, Zhang L. Event-related potentials elicited by social commerce and electronic-commerce reviews. Cogn Neurodyn. 2015;9(6):639-648. doi:10.1007/s11571-015-9353-1

11. Gajewski PD, Drizinsky J, Zülch J, Falkenstein M. ERP correlates of simulated purchase decisions. Front Neurosci. 2016;10(360). doi:10.33 89/fnins. 2016.00360

12. Chen M, Ma Q, Li M, Dai S, Wang X, Shu L. The neural and psychological basis of herding in purchasing books online: an Event-Related Potential Study. Cyberpsychol Behav Soc Netw. 2010;13(3):321-328. doi:10.1089/cyber.2009.0142

13. Schwarz N. Emotion, cognition, and decision making. Cogn Emot. 2000;14(4):433-440. doi:10.1080/026999300402745

14. Michel CM, Brunet D. EEG Source imaging: a practical review of the analysis steps. Front Neurol. 2019;10:325. doi:10.3389/fneur.2019.00325

15. Burle B, Spieser L, Roger C, Casini L, Hasbroucq T, Vidal F. Spatial and temporal resolutions of EEG: is it really black and white? A scalp current density view. Int $J$ Psychophysiol. 2015;97(3):210-220. doi:10.1016/j.ijpsycho.2015.05.004

16. Chen Y-F. Herd behavior in purchasing books online. Comput Human Behav. 2008;24(5):1977-1992. doi:10.1016/j.chb.2007.08.004

17. Park S, Nicolau JL. Asymmetric effects of online consumer reviews. Ann Tour Res. 2015;50(SupplementC):67-83. doi:10.1016/ j.annals.2014.10.007

18. Zhang Q, Kong L, Jiang Y. The interaction of arousal and valence in affective priming: behavioral and electrophysiological evidence. Brain Res. 2012;1474:60-72. doi:10.1016/j.brainres.2012.07.023

19. Zhang J, Zhou R. Individual differences in automatic emotion regulation affect the asymmetry of the LPP component. PLoS One. 2014;9(2):e88261. doi:10.1371/journal.pone.0088261

20. Aftanas LI, Koshkarov VI, Pokrovskaja VL, Lotova NV, Mordvintsev YN. Pre- and post-stimulus processes in affective task and event-related desynchronization (ERD): do they discriminate anxiety coping styles? Int J Psychophysiol. 1996;24(3):197-212. doi:10.1016/ S0167-8760(96)00060-8

21. Jensen O, Gelfand J, Kounios J, Lisman JE. Oscillations in the alpha band $(9-12 \mathrm{~Hz})$ increase with memory load during retention in a short-term memory task. Cereb Cortex. 2002;12(8):877-882. doi:10.1093/cercor/12.8.877

22. Klimesch W. Alpha-band oscillations, attention, and controlled access to stored information. Trends Cogn Sci. 2012;16(12):606-617. doi:10.1016/j.tics.2012.10.007

23. Cuthbert BN, Schupp HT, Bradley MM, Birbaumer N, Lang PJ. Brain potentials in affective picture processing: covariation with autonomic arousal and affective report. Biol Psychol. 2000;52 (2):95-111. doi:10.1016/S0301-0511(99)00044-7

24. Klimesch W, Pfurtscheller G, Schimke H. Pre- and post-stimulus processes in category judgement tasks as measured by event-related desynchronization (ERD). J Psychophysiol. 1992;6(3):185-203.

25. Hajcak G, MacNamara A, Olvet DM. Event-related potentials, emotion, and emotion regulation: an integrative review. Dev Neuropsychol. 2010;35(2):129-155. doi:10.1080/87565640903526504

26. Khan U, Dhar R. Price-framing effects on the purchase of hedonic and utilitarian bundles. J Soc Mark Res. 2010;47(6):1090-1099. doi:10.1509/jmkr.47.6.1090

27. Schupp HT, Markus J, Weike AI, Hamm AO. Emotional facilitation of sensory processing in the visual cortex. Psychol Sci. 2003;14 (1):7-13. doi:10.1111/1467-9280.01411

28. Renfroe JB, Bradley MM, Sege CT, Bowers D, Chao L. Emotional modulation of the late positive potential during picture free viewing in older and young adults. PLoS One. 2016;11(9):e0162323. doi:10.1371/journal.pone. 0162323 
29. Moran TP, Jendrusina AA, Moser JS. The psychometric properties of the late positive potential during emotion processing and regulation. Brain Res. 2013;1516:66-75. doi:10.1016/j.brainres. 2013.04.018

30. Loureiro SMC, Bilro RG, Japutra A. The effect of consumer-generated media stimuli on emotions and consumer brand engagement. J Prod Brand Manag. 2019. doi:10.1108/JPBM-112018-2120

31. Ullah R, Zeb A, Kim W. The impact of emotions on the helpfulness of movie reviews. J Appl Res Technol. 2015;13(3):359-363. doi:10.1016/j.jart.2015.02.001

32. Yan D, Sengupta J. Effects of construal level on the price-quality relationship. J Consum Res. 2011;38(2):376-389. doi:10.1086/659755

33. Gneezy A, Gneezy U, Lauga DO. A reference-dependent model of the price-quality heuristic. J Soc Mark Res. 2014;51(2):153-164. doi:10.1509/jmr.12.0407

34. Rao AR. The quality of price as a quality cue. J Soc Mark Res. 2005;42(4):401-405. doi:10.1509/jmkr.2005.42.4.401

35. Klimesch W. EEG alpha and theta oscillations reflect cognitive and memory performance: a review and analysis. Brain Res Rev. 1999;29 (2):169-195. doi:10.1016/S0165-0173(98)00056-3
36. Klimesch W, Schack B, Sauseng P. The functional significance of theta and upper alpha oscillations. Exp Psychol. 2005;52(2):99-108. doi:10.1027/1618-3169.52.2.99

37. Klimesch W, Doppelmayr M, Hanslmayr S. Upper alpha ERD and absolute power: their meaning for memory performance. In: Neuper C, Klimesch W, editors. Progress in Brain Research. Vol. 159. Elsevier; 2006:151-165.

38. Arakaki X, Lee R, King KS, Fonteh AN, Harrington MG, Ginsberg SD. Alpha desynchronization during simple working memory unmasks pathological aging in cognitively healthy individuals. PLoS One. 2019;14(1):e0208517. doi:10.1371/journal.pone.0208517

39. Marco-Pallares J, Cucurell D, Cunillera T, et al. Human oscillatory activity associated to reward processing in a gambling task. Neuropsychologia. 2008;46(1):241-248. doi:10.1016/j.neuropsychologia.2007.07.016

40. Roach BJ, Mathalon DH. Event-related EEG time-frequency analysis: an overview of measures and an analysis of early gamma band phase locking in schizophrenia. Schizophr Bull. 2008;34(5):907-926. doi:10.1093/schbul/sbn093
Psychology Research and Behavior Management

\section{Publish your work in this journal}

Psychology Research and Behavior Management is an international, peer-reviewed, open access journal focusing on the science of psychology and its application in behavior management to develop improved outcomes in the clinical, educational, sports and business arenas. Specific topics covered in the journal include: Neuroscience, memory and decision making; Behavior modification and management; Clinical

\section{Dovepress}

applications; Business and sports performance management; Social and developmental studies; Animal studies. The manuscript management system is completely online and includes a very quick and fair peer-review system, which is all easy to use. Visit http://www. dovepress.com/testimonials.php to read real quotes from published authors. 